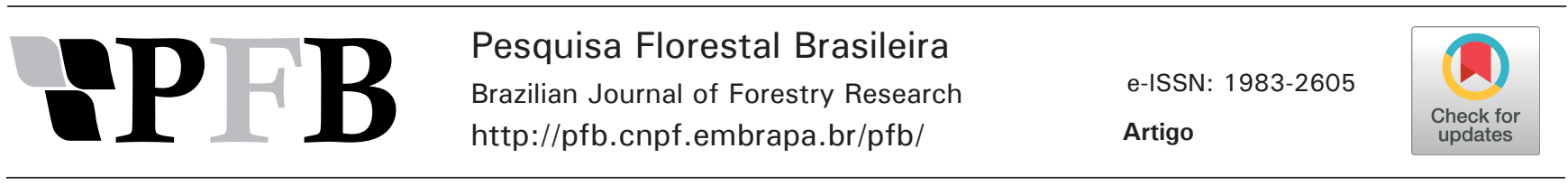

\title{
Influência do tamanho e da escarificação dos diásporos na emergência e estabelecimento de Pterodon emarginatus
}

Nayara Mesquita Mota ${ }^{1}$ (D), Evandro Alexandre Fortini (iD), Giovana Rodrigues da Luz ${ }^{3}$ (iD), Maria das Dores Magalhães Veloso ${ }^{3}$ (iD) Geraldo Wilson Fernandes ${ }^{4}$ (D), Yule Roberta Ferreira Nunes ${ }^{3 *}$ (ID)

${ }^{1}$ Universidade Federal de Viçosa, Departamento de Biologia Geral, Avenida P.H. Rolfs, s/nº, Centro, CEP 36570-900, Viçosa, MG, Brasil

Universidade Federal de Viçosa, Departamento de Biologia Vegetal, Avenida P.H. Rolfs, s/nº, Centro, CEP 36570-900, Viçosa, MG, Brasil

${ }^{3}$ Universidade Estadual de Montes Claros, Laboratório de Ecologia Vegetal, CP. 126, CEP 39401-089, Montes Claros, MG, Brasil

${ }^{4}$ Universidade Federal de Minas Gerais, Laboratório de Ecologia Evolutiva \& Biodiversidade, CP. 486, CEP 30161-970, Belo Horizonte, MG, Brasil

"Autor correspondente:

yule.nunes@unimontes.br

Termos para indexação:

Biometria

Dormência

Propagação vegetal

Index terms:

Biometry

Dormancy

Plant propagation

Histórico do artigo:

Recebido em 17/10/2018

Aprovado em 03/05/2019

Publicado em 31/12/2019

\section{(c) (1) $\Theta \Theta$}

Resumo - Esse trabalho buscou verificar a influência do tamanho dos diásporos e de tratamentos de escarificação sobre a taxa de emergência e crescimento inicial de Pterodon emarginatus Vog. (Fabaceae) após um ano de armazenamento. Diásporos da espécie foram medidos, pesados e separados em três classes de tamanho, com amplitude determinada pela largura do fruto, sendo submetidos posteriormente à escarificação térmica e mecânica. Foi utilizado um delineamento inteiramente casualizado, com 10 repetições. Foi realizada análise de sobrevivência, além de análise de variância e pósteste de Tukey, para verificar diferenças significativas na porcentagem de emergência dos diásporos. Para detectar a variação no crescimento inicial das plântulas utilizaram-se modelos lineares generalizados. Os tratamentos consorciados com os maiores diásporos influenciaram positivamente a porcentagem de emergência. Diásporos maiores também resultaram em plântulas com maiores diâmetros e maior comprimento do caule. A escarificação mecânica proporcionou maior alocação de biomassa nas raízes. Sugerese que diásporos de $P$. emarginatus sejam submetidos a tratamentos pré-germinativos, para potencializar a emergência e formação de plântulas, sendo recomendada a seleção dos diásporos maiores.

\section{Influence of size and scarification in the emergency and establishment of Pterodon emarginatus diaspores}

\begin{abstract}
This study aimed to verify the influence of the size of the diaspores and scarification treatments on the emergence rate and initial growth of Pterodon emarginatus Vog. (Fabaceae) after one year of storage. Diaspores of the species were collected, measured, weighed and separated into three size classes, with amplitude determined by the width of the fruit. Subsequently, they were submitted to thermal and mechanical scarification. A randomized experimental design was used, with 10 replicates of 10 units / each. We performed a survival analysis, besides analysis of variance and Tukey post-hoc test to verify significant differences in the percentage of diaspores emergence. We used generalized linear models to verify the variation in the initial growth of the seedlings. Our results indicated that treatments intercropped with the largest diaspore sizes positively influenced the percentage of emergence. Larger diaspores also resulted in larger diameter seedlings and stem length. Mechanical scarification led to a higher biomass allocation in the roots. We suggest that $P$. emarginatus diaspores should be submitted to pre-germination treatments to potentiate seedling emergence and development. We also recommend choosing the largest diaspores.
\end{abstract}




\section{Introdução}

A semente é o principal meio de reprodução das espermatófitas (Bewley et al., 2013; Elzenga \& Bekker, 2017) e o conhecimento de suas características é imprescindível para propagação de uma espécie em grande escala. As informações sobre variações biométricas de tamanho e peso dos frutos e sementes, e suas correlações, fornecem subsídios para seleção de sementes com boa qualidade fisiológica e maior potencial e vigor de germinação (Souza et al., 2016; Saldanha et al., 2018). Sementes maiores, por exemplo, podem apresentar melhor qualidade fisiológica e, assim, índices superiores de germinação se comparadas as de menor tamanho (Popinigis, 1977; Westoby et al., 2002; Souza \& Fagundes, 2014; Smith, 2018).

Sob condições ambientais favoráveis, as sementes podem reiniciar o crescimento do embrião e germinar, exceto quando apresentam algum tipo de dormência (Popinigis, 1977; Bewley et al., 2013). A dormência é considerada tegumentar ou física quando estruturas como o pericarpo, o tegumento e as paredes celulares restringem as trocas gasosas ou a entrada de água (Popinigis, 1977). Na família Fabaceae, a testa com paredes celulares grossas e lignificadas, impregnadas com substâncias de natureza hidrofóbicas, confere a principal resistência à entrada de água (Pereira et al., 2014). Esse tipo de dormência pode ser reduzida ou eliminada através de tratamentos pré-germinativos, como a escarificação dos diásporos (Popinigis, 1977). A escarificação térmica (imersão em água quente) e a mecânica estão entre os tratamentos mais utilizados em diásporos com envoltório lenhoso, por diminuir a resistência do tegumento e levar à formação de orifícios que favorecem a entrada de água e as trocas gasosas (Popinigis, 1977; Matos et al., 2007), o que pode acelerar o processo de germinação. Em algumas espécies de Fabaceae, a escarificação e a incisão do tegumento são métodos eficientes, mas algumas vezes estes métodos são ineficientes devido ao aumento das porcentagens de plântulas infectadas ou de sementes mortas (Pereira et al., 2014; Arruda et al., 2015).

A plântula consiste no estádio posterior à germinação do embrião (Melo et al., 2004). Tal como no processo de germinação, o tamanho da semente está diretamente relacionado com o sucesso no estabelecimento da plântula (Westoby et al., 2002; Smith, 2018). Isso porque o tamanho inicial das plântulas está positivamente relacionado ao tamanho da semente entre espécies e dentro da mesma espécie, e plântulas de sementes maiores tendem a ter mais reservas (Westoby et al., 2002). Nessa fase, a taxa de mortalidade é extremamente elevada e, por isso, representa uma das etapas mais críticas no ciclo de vida das plantas (Statton et al., 2017). A escarificação ou a incisão do tegumento da semente, por exemplo, pode causar injúrias aos cotilédones e comprometer a formação de plântulas normais (Pereira et al., 2014). Entretanto, estudos associados à esta fase do ciclo de vida das plantas ainda são incipientes, visto que a maioria dos trabalhos investigam apenas a porcentagem de germinação e não o desenvolvimento subsequente das plântulas (Pereira et al., 2014).

Pterodon emarginatus Vog, popularmente conhecida como sucupira branca, faveiro ou sucupira lisa, é uma espécie da família Fabaceae, muito utilizada no paisagismo ornamental, na produção de madeira e na medicina popular (Almeida et al., 1998). O óleo essencial e os compostos isolados das suas folhas possuem potencial farmacológico e podem ser explorados para a obtenção de compostos bioativos (Santos et al., 2010). Essa espécie é clímax, heliófita e seletiva xerófita, típica do cerrado e da transição deste bioma para a floresta semidecídua (Lorenzi, 1992; Almeida et al., 1998; Lima et al., 2017). Floresce de setembro a outubro e a maturação dos frutos ocorre nos meses de junho-julho, permanecendo na árvore por mais algum tempo (Lorenzi, 1992). Encontrada principalmente em terrenos secos e arenosos, pode compor programas de reflorestamentos destinados à recuperação de áreas degradadas, devido às suas características de tolerância à alta incidência luminosa e baixa exigência nutricional (Lorenzi, 1992). Entretanto, está relacionada na lista de espécies ameaçadas da flora de Minas Gerais, considerada vulnerável à extinção (Fundação Biodiversitas, 2007). Portanto, são necessários estudos que visem o entendimento da propagação desta espécie, buscando sua recuperação, bem como otimização do seu uso nos programas de reflorestamento.

Apesar de haver alguns trabalhos realizados com P. emarginatus (Reis et al., 1980; Reis et al., 1985; Coelho et al., 2001; Ferreira et al. 2001; Matos et al., 2007; Terra et al., 2007), a formação de suas plântulas foi poucas vezes determinada, além de nenhum estudo avaliar a eficiência de tratamentos pré-germinativos no seu desenvolvimento e a influência do tamanho do diásporo na sua formação. As técnicas que facilitam 
a germinação e o estabelecimento de plântulas estão diretamente relacionadas com processo de produção de mudas e com o processo de regeneração das comunidades vegetais (Larson et al., 2015; Ceccon et al., 2016). Portanto, estudos que contemplem a conservação, germinação e longevidade de sementes são relevantes para a conservação da flora e para a produção de mudas de espécies nativas (Broadhurst et al., 2016). Assim, esse estudo teve como objetivo caracterizar biometricamente os diásporos de $P$. emarginatus e verificar se o tamanho e diferentes tratamentos de escarificação interferem na emergência e estabelecimento inicial (crescimento e biomassa) das plântulas da espécie.

\section{Material e métodos}

\section{Coleta dos diásporos}

A coleta dos diásporos foi realizada em novembro de 2008, na Área de Proteção Ambiental (APA) do Rio Pandeiros, que apresenta uma área de 393 mil ha, dividida em várias fisionomias vegetais, onde se destacam o cerrado, as matas secas calcárias, as matas ciliares, as veredas e as áreas de planícies alagáveis (Nunes et al., 2009).

Esta APA abrange os municípios de Januária, Bonito de Minas e Cônego Marinho e localiza-se aproximadamente a $220 \mathrm{~km}$ da cidade de Montes Claros, norte de Minas Gerais (Nunes et al., 2009). O clima da região é considerado do tipo semiárido, com estações bem definidas e temperatura média anual de $21{ }^{\circ} \mathrm{C}$ a $24{ }^{\circ} \mathrm{C}$. As chuvas são concentradas nos meses de novembro a janeiro, com precipitação anual média entre 900 a 1200 mm (INMET, 1931-2000). Os solos encontrados na região da APA são principalmente dos tipos Neossolo (com boa permeabilidade), Cambissolo (textura arenosa com baixa fertilidade natural) e Gleissolo (típicos de terrenos inundáveis) (Nunes et al., 2009).

Foram coletados diásporos de oito indivíduos reprodutivos sadios da espécie, que estavam localizados especificamente próximo ao Refúgio de Vida Silvestre

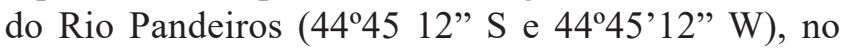
município de Januária, MG. Os diásporos foram acondicionados em sacos plásticos devidamente identificados e conduzidos ao Laboratório de Ecologia Vegetal (LEVE), no campus da Universidade Estadual de Montes Claros (Unimontes).

\section{Caracterização biométrica e tratamentos de escarificação}

Foram selecionados 900 diásporos que não apresentavam dano aparente, sendo medidos em comprimento (sentido longitudinal), largura (sentido transversal) e espessura. Todas as medidas foram realizadas com o auxílio de paquímetro digital (modelo DIGIMESS0 $($ ) e, posteriormente, todos os diásporos foram pesados em balança eletrônica de precisão (modelo AG/HAGEAKAÒ).

A partir da análise biométrica, por correlação de Pearson (r), foram determinadas três classes de tamanho (pequenas, médias e grandes) para o experimento de germinação. A variável selecionada para determinar a amplitude das classes de tamanho foi a largura do fruto, por apresentar maior número de correlações significativas com as demais variáveis (vide resultados). A partir disso, foram selecionados 900 diásporos, que foram divididos nas três classes de tamanho definidas pela largura do fruto: pequenos $(8,10$ a $14,27 \mathrm{~mm})$, médios $(14,28$ a $16,15 \mathrm{~mm})$ e grandes $(16,16$ a 22,05 $\mathrm{mm})$.

Os diásporos, separados por classes de tamanho, foram submetidos aos seguintes tratamentos pré-germinativos: escarificação térmica - onde foram imersos em água quente a $70{ }^{\circ} \mathrm{C}$, permanecendo até que a temperatura da água abaixasse para $50{ }^{\circ} \mathrm{C}$, em torno de $30 \mathrm{~min}$; escarificação mecânica - diásporos foram escarificados pelo corte de uma pequena parte da extremidade do diásporo e do tegumento da semente, com a utilização de uma tesoura de poda, de modo a não danificar o embrião; e controle - diásporos foram mantidos intactos.

\section{Emergência de plântulas}

$\mathrm{O}$ experimento foi conduzido em casa de vegetação com tetos de plástico e laterais de sombrite, em dezembro de 2009. Os diásporos foram semeados a $1,5 \mathrm{~cm}$ de profundidade do solo, em sacos plásticos pretos de polietileno de $3 \mathrm{~kg}$, contendo uma mistura de terra e areia na proporção de 3:1 respectivamente (Figura 1), com irrigação periódica ao longo de 148 dias. O delineamento experimental foi inteiramente casualizado em um arranjo fatorial $3 \times 3$, consistido de três classes de tamanhos de diásporos (pequenas, médias e grandes) e três tratamentos de quebra de dormência (controle, escarificação térmica e escarificação mecânica), com 10 repetições de 10 sacos. Foram considerados germinados 
os diásporos que apresentaram emergência do caulículo na superfície do solo (Reis et al., 1980; Figura 1B).

\section{Crescimento inicial de plântulas e alocação de biomassa}

Foram medidas as plântulas que adquiriram altura mínima de $2 \mathrm{~cm}$ e folhas definidas. Foram selecionadas apenas as plântulas que puderam ser avaliadas durante o período de 90 dias $(n=68)$, excluindo aquelas que germinaram posteriormente. As plântulas recrutadas foram avaliadas em um total de seis observações, realizadas quinzenalmente. Foram mensurados: a altura total $(\mathrm{cm})$, com o auxílio de uma régua graduada, desde o colo até a última gema apical do ramo principal; o diâmetro à altura do solo (DAS, em mm), através do uso de paquímetro digital (modelo DIGIMESS0®); e o número total de folhas, através da contagem.

Após 30 dias do término das avaliações do crescimento inicial das plântulas e seis meses após a semeadura, as plântulas foram cuidadosamente retiradas dos sacos de polietileno, lavadas e suas partes separadas em raízes, caule e folhas. Para avaliar a alocação de biomassa, foram selecionadas 100 plântulas aleatoriamente, que germinaram no decorrer do experimento. $O$ caule e a raiz principal foram medidos em comprimento, com régua graduada, e as folhas foram contadas. Posteriormente, essas partes foram colocadas em embalagens de papel alumínio e desidratadas em estufa de ventilação forçada a $72^{\circ} \mathrm{C}$, até alcançar peso constante. As partes secas foram pesadas $(\mathrm{g})$ em balança eletrônica de precisão (modelo AG/HAGEAKAÒ). As embalagens foram pesadas separadamente do material vegetal, e a diferença do peso seco e das embalagens foi considerada para a análise.

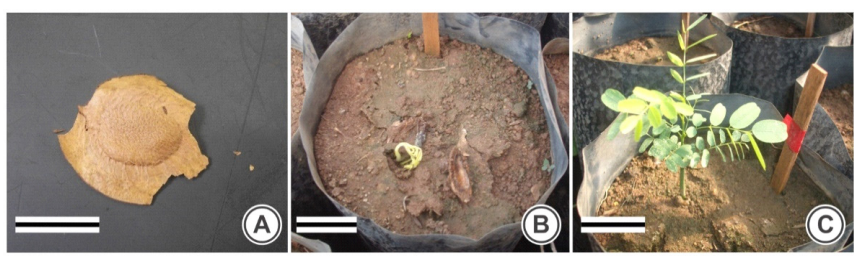

Figura 1. A - Diásporos de Pterodon emarginatus (barra de escala $=1 \mathrm{~cm}$ ); B - Início da emergência das plântulas, 25 dias após semeadura (barra de escala $=5 \mathrm{~cm}$ ); C - Plântula após 90 dias da germinação (barra de escala $=5 \mathrm{~cm}$ ).

Figure 1. A - Diaspores of Pterodon emarginatus (bar scale = $1 \mathrm{~cm})$; B - Early emergence of seedlings, 25 days after sowing (scale bar $=5 \mathrm{~cm}) ; \mathrm{C}$ - Seedling after 90 days of germination $($ scale bar $=5 \mathrm{~cm})$.

\section{Análise dos dados}

Para a caracterização biométrica realizaram-se análises estatísticas descritivas de cada medida avaliada. Nessas análises, as medidas biométricas foram correlacionadas entre si através do coeficiente de correlação de Pearson (r), sendo obtido o valor de $\mathrm{p}$ da correlação.

Para verificar diferenças na porcentagem de emergência das plântulas entre as classes de tamanho e os tratamentos pré-germinativos, foi feita análise de variância (ANOVA) e o pós-teste de Tukey (Zar, 2010) para os primeiros 30 dias de avaliação, após a emergência da primeira plântula. Anterior ao teste, os dados de porcentagem de germinação, por se tratarem de dados binários, foram transformados em arcoseno da raiz da porcentagem, para linearização dos mesmos.

A análise de sobrevivência foi utilizada para detectar o efeito dos tratamentos e do tamanho na emergência de plântulas através do pacote 'survival' (Therneau, 2014), utilizando o software R 2.5 (R Development Core Team). Através da análise de sobrevivência verifica-se a probabilidade de germinação em um certo período, evitando-se a pseudo-replicação temporal (Souza \& Fagundes, 2014). Para essa análise foi considerado todo o período de avaliação do experimento (148 dias). Além disso, foi calculado o índice de velocidade de emergência (IVE), aos 10, 30 e 60 dias após a emergência da primeira plântula.

$$
\mathrm{IVE}=\frac{\mathrm{E} 1}{\mathrm{~N} 1}+\frac{\mathrm{E} 2}{\mathrm{~N} 2}+\cdots+\frac{\mathrm{En}}{\mathrm{Nn}}
$$

Em que: E1, E2 e En = número de plântulas normais computadas na primeira, segunda e última contagem; N1, $\mathrm{N} 2$ e Nn = número de dias após a primeira plântula emergir (Maguire, 1962).

Foram utilizados modelos lineares generalizados (GLM), para verificar diferenças significativas no estabelecimento e na biomassa final das plântulas, entre as classes de tamanho e os tratamentos pré-germinativos, através do programa estatístico Statistica 7.0 (Statsoft Inc, 2011). Para a comparação de média dos tamanhos e tratamentos significativos foi feito o pós-teste de Tukey (Zar, 2010). Para todas as análises, o nível de significância adotado foi $\mathrm{p} \leq 0,05$. 


\section{Resultados}

\section{Relações biométricas}

Considerando todos os diásporos coletados, as variáveis biométricas da espécie apresentaram maior frequência de diásporos em intervalos de valores medianos, com exceção da variável largura do fruto, que concentrou a maior parte dos diásporos no menor intervalo (Tabela 1). Como a amplitude das classes de tamanho teve a largura do fruto como referência, nota-se que a maioria dos diásporos coletados pertence às classes de tamanho pequeno e médio.

Para o comprimento do fruto, verificou-se que a maioria (71\%) enquadrou-se nos valores de 20,01 a $27,00 \mathrm{~mm}$ (Tabela 1). Para a largura, houve concentração dos diásporos (63\%) no intervalo de 8,00 a $16,00 \mathrm{~mm}$. Os maiores percentuais da espessura (72\%) concentraram-se entre 4,64 a 7,46 mm. O peso apresentou $78 \%$ do grupo de diásporos a acima de $0,75 \mathrm{~g}$.

Foram observadas correlações significativas entre os parâmetros biométricos comprimento e largura dos frutos $(\mathrm{r}=0,63 ; \mathrm{p}<0,001)$ e largura e peso dos frutos $(\mathrm{r}=0,61 ; \mathrm{p}<0,001)$. A largura do fruto também se relacionou com o peso $(r=0,73 ; p<0,001)$. Valores menores de correlação de Pearson foram encontrados na relação entre a espessura do fruto com a largura $(r=0,31$; $\mathrm{p}<0,001)$ e com o peso $(\mathrm{r}=0,41 ; \mathrm{p}<0,001)$. As altas correlações encontradas entre os parâmetros biométricos dos frutos mostram que há uma relação direta do aumento de um parâmetro biométrico com outro.

Tabela 1. Biometria dos frutos e das plântulas de Pterodon emarginatus provenientes de oito matrizes do Refúgio de Vida Silvestre do Rio Pandeiros, MG).

Table 1. Biometry of fruits and seedlings of Pterodon emarginatus from eight mother trees of Pandeiros River Reserve, MG.

\begin{tabular}{lccc}
\hline \multicolumn{1}{c}{ Fruto/Diásporo } & Valor máximo & Valor mínimo & Valor médio \pm desvio padrão \\
\hline Comprimento $(\mathrm{mm})$ & 33,56 & 13,50 & $21,85 \pm 3,01$ \\
Largura $(\mathrm{mm})$ & 36,76 & 8,10 & $15,31 \pm 2,28$ \\
Espessura $(\mathrm{mm})$ & 13,84 & 1,89 & $5,30 \pm 1,02$ \\
Peso $(\mathrm{g})$ & 2,00 & 0,12 & $0,97 \pm 0,28$ \\
\hline \multicolumn{1}{c}{$\quad$ Plântula } & & & \\
\hline Massa seca das raízes $(\mathrm{g})$ & 2,11 & 0,03 & $0,69 \pm 0,53$ \\
Massa seca do caule $(\mathrm{g})$ & 1,04 & 0,01 & $0,35 \pm 0,23$ \\
Massa seca das folhas $(\mathrm{g})$ & 1,80 & 0,02 & $0,55 \pm 0.42$ \\
Comprimento do caule $(\mathrm{cm})$ & 20,00 & 3,60 & $10,72 \pm 3,41$ \\
Comprimento da raiz $(\mathrm{cm})$ & 56,00 & 6,00 & $28,50 \pm 9,01$ \\
Número de folhas & 25,00 & 2,00 & $13,39 \pm 4,21$ \\
\hline
\end{tabular}

\section{Emergência de plântulas}

Após 30 dias do início da primeira emergência, os tratamentos pré-germinativos $(\mathrm{gl}=2 ; \mathrm{F}=4,76 ; \mathrm{p}=$ $0,011 ; \mathrm{n}=90)$ e a interação entre os tratamentos e o tamanho dos diásporos $(\mathrm{gl}=4 ; \mathrm{F}=3,73 ; \mathrm{p}=0,007 ; \mathrm{n}=$ 90) influenciaram significativamente a porcentagem de emergência (Figura 2). O maior percentual foi observado nos tratamentos de escarificação térmica $(\overline{\mathrm{X}}=6,77 \pm$
$0,69 \%$ ) e mecânica $(\bar{X}=7,93 \pm 0,95 \%)$. Os maiores percentuais de emergência em diásporos pequenos foram observados no tratamento de escarificação térmica $(\overline{\mathrm{X}}=12,00 \pm 1,28 \%)$. Para os diásporos médios, o tratamento de escarificação mecânica mostrou-se mais eficiente $(\overline{\mathrm{X}}=13,00 \pm 1,12 \%)$. Enquanto que, para os diásporos grandes, não foram observadas diferenças significativas entre os tratamentos de escarificação e o controle no percentual de emergência das plântulas. 


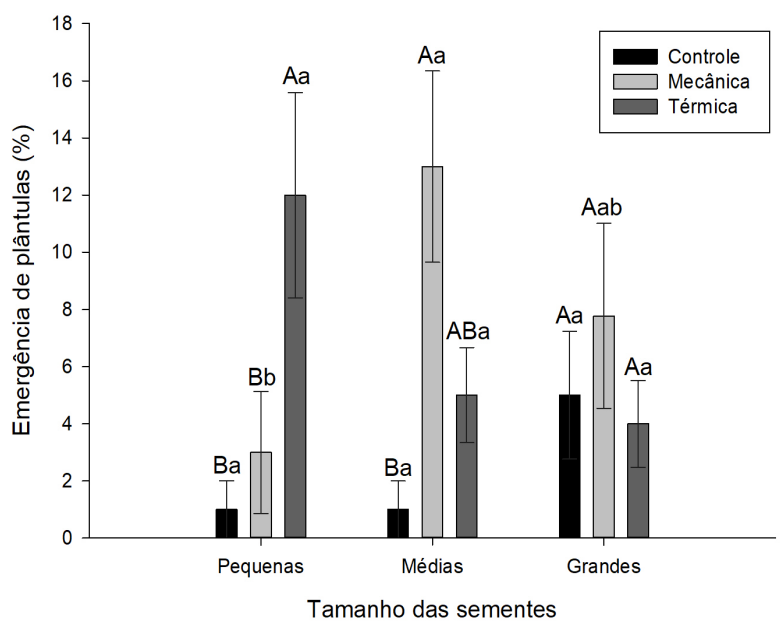

Figura 2. Porcentagem de emergência de plântulas advindas de diásporos pequenos, médios e grandes de Pterodon emarginatus (média \pm erro padrão) provenientes de oito matrizes do Refúgio de Vida Silvestre do Rio Pandeiros, MG, mediante diferentes tratamentos pré-germinativos após 30 dias de avaliação. Letras maiúsculas comparam médias dos diferentes níveis de tamanho de diásporo e letras minúsculas comparam as médias dos tratamentos de escarificação. Médias seguidas pela mesma letra não diferem entre si pelo teste de Tukey, a 5\% de probabilidade.

Figure 2. Percentage of seedlings emergence from small, medium and large diaspores of Pterodon emarginatus (mean \pm standard error), from eight mother trees of Pandeiros River Reserve, MG, by different pre-germination treatments after 30 days of evaluation. Upper case letters compare averages of different levels of diaspore size and lower case letters compare the means of scarification treatments. Means followed by the same letter do not differ by Tukey test, at $5 \%$ probability.

Ainda em relação aos tratamentos de escarificação, de acordo com a análise de sobrevivência, os diásporos que passaram por escarificação mecânica diferiram daqueles que passaram por escarificação térmica e do controle $(\mathrm{p}<$ $0,001)$, não havendo diferenças significativas entre esses dois últimos. Sendo assim, a escarificação mecânica foi mais eficiente, considerando todo o período de avaliação (140 dias).

As menores porcentagens de germinação foram encontradas para diásporos pequenos e médios do tratamento controle ( $\overline{\mathrm{X}}=1,00 \pm 0,10 \%)$. O tamanho do diásporo não afetou as porcentagens de emergência após 30 dias de avaliação $(p>0,05)$. Entretanto, considerando a análise de sobrevivência, não só os tratamentos de escarificação como as classes de tamanho apresentaram diferenças significativas na emergência de plântulas. Os diásporos da menor classe de tamanho diferiram dos diásporos da classe de tamanho média e grande, portanto, é possível inferir que o tamanho das sementes está associado ao sucesso germinativo das mesmas.

Os valores mais altos do índice de velocidade de emergência (IVE) das sementes de $P$. emarginatus foram dos diásporos médios e daqueles que passaram por tratamento de escarificação mecânica (Tabela 2). Após 60 dias de avaliação, a emergência de plântulas que não passaram por tratamento aumentou, mas ainda assim, o maior IVE foram dos diásporos médios que foram submetidos à escarificação mecânica.

Tabela 2. Índice de velocidade de emergência (IVE) calculado para 10, 30 e 60 dias após a primeira emergência de diásporos de Pterodon emarginatus provenientes de oito matrizes do Refúgio de Vida Silvestre do Rio Pandeiros, MG.

Table 2. Speed emergency index calculated for 10/30/60 days after the first emergency of Pterodon emarginatus diaspores from eight mother trees of Pandeiros River Reserve, MG.

\begin{tabular}{lccc}
\hline Tratamento*Tamanho & IVE 10 dias & IVE 30 dias & IVE 60 dias \\
\hline Mecânica/pequenas & 0,014 & 0,016 & 0,954 \\
Mecânica/médias & $\mathbf{0 , 0 9 8}$ & $\mathbf{0 , 2 3 7}$ & $\mathbf{2 , 1 1 7}$ \\
Mecânica/grandes & 0,023 & 0,060 & 1,247 \\
Térmica/pequenas & 0,042 & 0,105 & 1,509 \\
Térmica/médias & 0,053 & 0,075 & 0,829 \\
Térmica/grandes & 0 & 0,021 & 0,827 \\
Controle/ pequenas & 0 & 0,103 & 0,658 \\
Controle/médias & 0,050 & 0,050 & 1,080 \\
Controle/grandes & 0,033 & 0,055 & 1,058 \\
\hline Tratamentos & & & \\
\hline Mecânica & $\mathbf{0 , 0 7 8}$ & $\mathbf{0 , 1 0 4}$ & $\mathbf{1 , 4 3 9}$ \\
Térmica & 0,031 & 0,067 & 1,055 \\
Controle & 0,028 & 0,070 & 0,932 \\
\hline Tamanhos & & & \\
\hline Pequenas & 0,014 & 0,080 & 0,994 \\
Médias & $\mathbf{0 , 0 9 8}$ & $\mathbf{0 , 1 2 1}$ & $\mathbf{1 , 3 4 2}$ \\
Grandes & 0,023 & 0,046 & 1,044 \\
\hline
\end{tabular}

Os valores em negrito são aqueles mais altos em cada classe dentro de cada período

Crescimento inicial de plântulas e alocação de biomassa

Cinco meses após a implantação do experimento e da semeadura, as plântulas selecionadas para a avaliação do crescimento inicial $(n=68)$ variaram de 1,15 a $5,52 \mathrm{~mm}$ 
de diâmetro à altura do solo (DAS), 3,5 a $20 \mathrm{~cm}$ de altura e 4 a 21 folhas por indivíduo (Tabela 1). O crescimento em diâmetro das plântulas de P. emarginatus variou entre as classes de tamanho $(\mathrm{gl}=2, \mathrm{~F}=3,81$, $\mathrm{p}$ $=0,020)$, com diferenças entre os diásporos grandes $(\overline{\mathrm{X}}=2,06 \pm 0,10)$ em relação aos pequenos $(\overline{\mathrm{X}}=1,60 \pm$ 0,13; Figura 3). Entretanto, em relação aos tratamentos pré-germinativos e na interação tratamento $\times$ tamanho, não foram observadas diferenças no crescimento em diâmetro das plântulas. Do mesmo modo, o crescimento em altura e o número de folhas não variou entre os tratamentos pré-germinativos, entre as classes de tamanho e na interação entre ambos.

Considerando a média dos 100 indivíduos recrutados para avaliação da alocação de biomassa, as plântulas apresentaram maior acúmulo de massa seca na parte aérea $(58 \%)$, desses $22 \%$ no caule e $36 \%$ nas folhas. A biomassa seca das raízes das plântulas de $P$. emarginatus ( $42 \%$ da massa seca total) variou entre os tratamentos pré-germinativos $(\mathrm{gl}=2, \mathrm{~F}=3,13, \mathrm{p}=0,050$; Figura 4), com diferenças entre os diásporos lixados mecanicamente em relação ao controle. No entanto, em relação às classes de tamanho e na interação tratamento $\times$ tamanho, não foram observadas diferenças na biomassa das raízes. Do mesmo modo, a biomassa seca do caule e a biomassa das folhas não apresentou diferença em relação às classes de tamanho, aos tratamentos pré-germinativos e na interação tratamento $\times$ tamanho. $\mathrm{O}$ comprimento final do caule variou entre as classes de tamanho $(\mathrm{g} 1$ $=2, \mathrm{~F}=3,71, \mathrm{p}=0,028$; Figura 5), mas não entre os tratamentos pré-germinativos e na interação tratamento $\times$ tamanho. O comprimento da raiz e o número de folhas final também não variaram em relação às variáveis tamanho e tratamento.

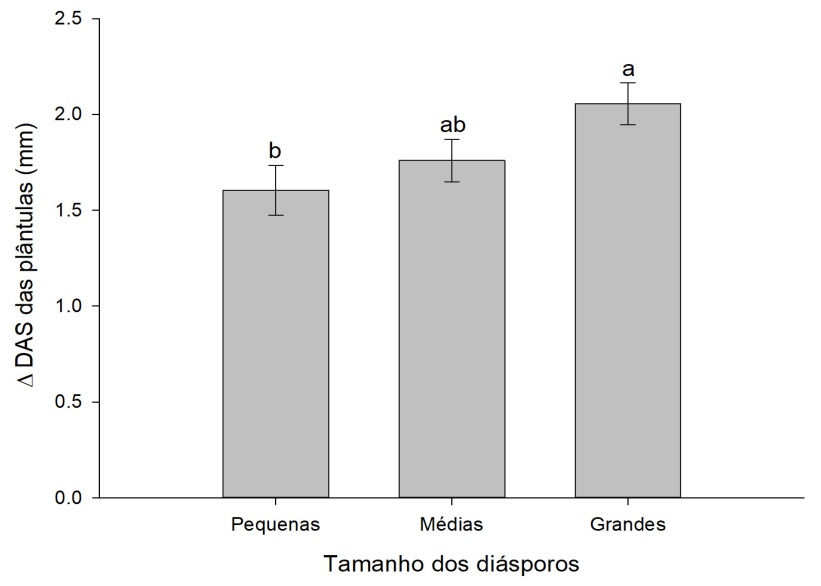

Figura 3. Diferença entre a primeira e a última medida do diâmetro à altura do solo $(\triangle \mathrm{DAS})$ das plântulas oriundas de diásporos pequenos, médios e grandes de Pterodon emarginatus (média \pm erro padrão) provenientes de oito matrizes do Refúgio de Vida Silvestre do Rio Pandeiros, MG.

Figure 3. Difference between the first and last diameter of soil height measure ( $\Delta \mathrm{DSH}$ ) of seedlings from small, medium and large diaspores of Pterodon emarginatus (mean \pm standard error) from eight mother trees of Pandeiros River Reserve, MG.

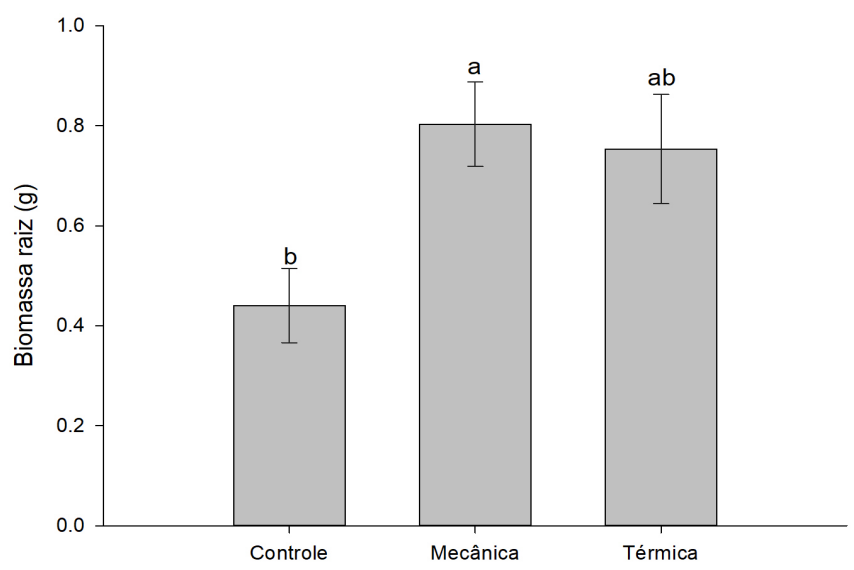

Figura 4. Massa seca (média \pm erro padrão) das raízes das plântulas de Pterodon emarginatus oriundas de diásporos provenientes de oito matrizes do Refúgio de Vida Silvestre do Rio Pandeiros, MG, submetidos a tratamentos de escarificação e o grupo controle.

Figure 4. Root dry weight (mean \pm standard error) of Pterodon emarginatus seedlings from diaspores from eight mother trees of Pandeiros River Reserve, MG, undergoing scarification treatments and control group. 


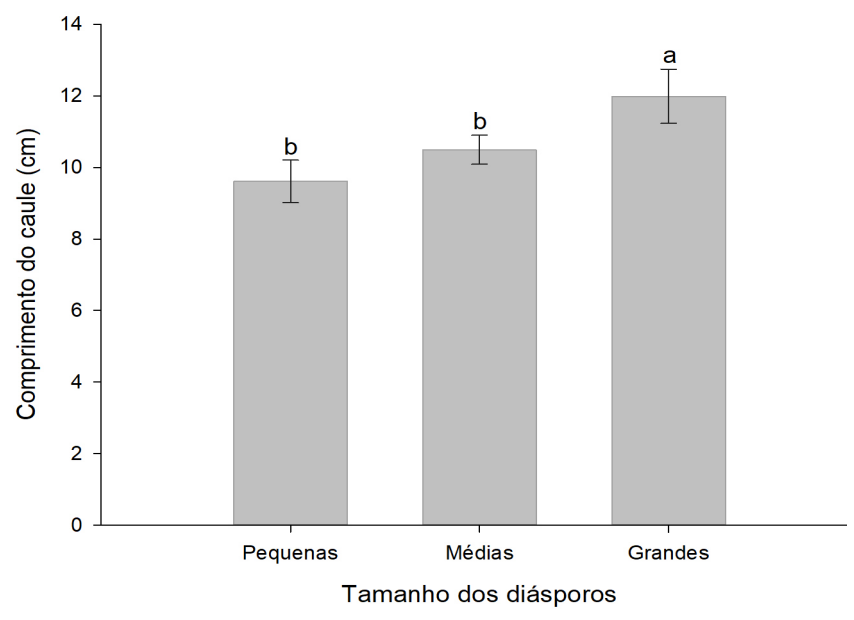

Figura 5. Comprimento final (média \pm erro padrão) do caule das plântulas de Pterodon emarginatus oriundas de diásporos de diferentes classes de tamanho, provenientes de oito matrizes do Refúgio de Vida Silvestre do Rio Pandeiros, MG.

Figure 5. Final length (mean \pm standard error) of the stem of Pterodon emarginatus seedlings from diaspores of different size classes, from eight mother trees of Pandeiros River Reserve, MG.

\section{Discussão}

As medidas biométricas de comprimento, largura e peso do fruto correspondem ao encontrado por Terra et al. (2007) em 50 unidades provenientes de 30 matrizes, confirmando que a morfologia da espécie é bastante homogênea e confiável para identificação (Ferreira et al., 2001). O início da emergência dos diásporos ocorreu 25 dias após a semeadura, e continuou até o $140^{\circ}$ dia. De acordo com Almeida et al. (1998), a germinação da sucupira branca inicia-se em torno de 30 a 50 dias. Espécies que ocorrem em ambientes com climas imprevisíveis e sazonais apresentam essa característica, uma germinação lenta e espaçada no tempo. Esse padrão reduz a probabilidade de um lote de sementes inteiro germinar em resposta a um estímulo ambiental em um momento inadequado para o crescimento das plântulas, tal como em uma chuva esporádica durante a estação seca (Doussi \& Thanos, 2002; Saboya \& Borghetti, 2012).

A porcentagem de emergência encontrada (13\%) foi inferior a de outros trabalhos que avaliaram a germinação da espécie, que geralmente varia entre 55 e 97\% (Reis et al., 1985; Coelho et al., 2001; Matos et al., 2007). A baixa taxa de emergência pode estar diretamente relacionada com o período de armazenamento dos diásporos, que pode ter influenciado a viabilidade do embrião e a formação de plântulas. Sendo assim, apesar das sementes da espécie se manterem viáveis até quatro anos de armazenamento (Almeida et al.; 1998), para sua propagação, o ideal é utilizar os diásporos logo após a colheita, uma vez que um ano de armazenamento já resultou em baixa emergência. Outro fato que pode ter causado a baixa emergência de plântulas, é que parte dos diásporos de sucupira não formam sementes, e quase a metade dos diásporos externamente perfeitos apresentam sementes atrofiadas ou rudimentares (Almeida et al., 1998; Ferreira et al., 2001; Terra et al., 2007). Apenas entre 26 e 48\% dos frutos formam sementes potencialmente viáveis (Ferreira et al., 2001; Terra et al., 2007). Esse tipo de triagem não foi realizada no presente estudo. Portanto, recomenda-se a avaliação das sementes anterior à semeadura.

Os resultados encontrados demonstram que a escarificação mecânica dos diásporos potencializa o sucesso na propagação da sucupira branca (Coelho et al., 2001; Ferreira et al., 2001; Terra et al., 2007). Métodos alternativos de quebra de dormência, tais como a utilização de ácido sulfúrico (escarificação química), choque térmico e embebição em água, não foram tão eficientes na germinação dessa espécie (Matos et al., 2007). Substâncias reguladoras de crescimento, como o ácido giberélico e o ácido 2-cloroetil fosfônico, também não influenciaram a taxa de germinação, sendo que apenas o corte no tegumento foi efetivo (Reis et al., 1985). Em sucupira branca, supõem-se que os inibidores químicos não estejam diretamente envolvidos no processo de germinação, visto que o simples enfraquecimento do tegumento resulta em aumento no potencial germinativo (Reis et al., 1985).

O tempo de imersão e a exposição à água quente são cruciais para o embrião, podendo causar a sua morte $\mathrm{e}$ afetar negativamente a taxa de germinação (Costa et al., 2010). Neste estudo com a sucupira branca, notou-se que os diásporos não apresentaram fragilidade à alta temperatura. Silva et al. (2016) demonstraram com seus experimentos que a água quente também se comporta de forma positiva para a germinação e o estabelecimento de Guazuma ulmifolia, sendo uma boa opção para a espécie. À imersão em água a $70{ }^{\circ} \mathrm{C}$ não foi capaz de superar a dormência física de Dimorphandra mollis, resultando em porcentagem germinativa similar à do controle (Oliveira et al., 2008). Geralmente, para espécies de 
Fabaceae, a escarificação térmica é um tratamento ineficiente de superação ou quebra de dormência (Pereira et al., 2014). No entanto, dentre os tratamentos testados no nosso trabalho, a imersão em água quente foi eficaz, principalmente em diásporos pequenos, mais do que a remoção de parte do envoltório. Deste modo, quando o interesse for trabalhar com diásporos pequenos, a escarificação térmica seria mais adequada por enfraquecer o tegumento de maneira mais satisfatória que a remoção de uma parte dele.

De forma geral, sementes maiores apresentam maior porcentagem de germinação e originam plântulas mais vigorosas (Popinigis, 1977; Vendramin \& Carvalho, 2013; Pereira et al. 2013; Saldanha et al., 2018). Sendo assim, o tamanho da semente pode indicar sua qualidade fisiológica, visto que dentro de um mesmo lote as sementes pequenas apresentam menor germinação, possivelmente devido à formação e acúmulo de nutrientes pelos maiores embriões nas sementes maiores (Popiginis, 1977; Biruel et al., 2010). Além disso, sementes de maior tamanho podem antecipar o crescimento (Pereira et al., 2013). Segundo Melo et al. (2004), a quantidade e o tipo das reservas das sementes influenciam de forma significativa no estabelecimento das plântulas. A reserva das sementes são a fonte inicial de energia e nutrientes do embrião, até se tornar fotossintetizante, de modo que grandes sementes resultam em plântulas maiores (Rose \& Poorter, 2002; Westoby et al., 2002; Souza \& Fagundes, 2014). Nesse estudo, o tamanho do diásporo afetou a probabilidade de emergência da plântula (medida através da análise de sobrevivência) e foi o único fator que influenciou no estabelecimento, no qual diásporos da classe de tamanho grande apresentaram plântulas com maior diâmetro do caule. Além disso, plântulas advindas de diásporos maiores tiveram maior comprimento final do caule. Assim, é provável que as plântulas de sucupira branca disponibilizam as reservas do propágulo primeiramente para o crescimento em diâmetro e posteriormente para o crescimento em altura.

De acordo com Rose \& Poorter (2002), as vantagens das sementes maiores também estão associadas com a sobrevivência à sombra, característica de espécies clímaceas, como a sucupira branca, uma espécie classificada como secundária tardia (Prado-Júnior et al., 2010). No entanto, na sucupira branca diásporos maiores não produziram plântulas com mais biomassa em quaisquer partes da plântula. O que significa que sementes de diversos tamanhos podem ter o mesmo padrão de alocação de biomassa. Nascimento et al. (2011) discutem que espécies florestais apresentam grande similaridade na alocação de biomassa, principalmente em espécies de crescimento lento como as secundárias tardias e climácicas. Sendo assim, o tamanho do diásporo da sucupira branca não é uma característica que provoca diferenças na massa seca final da plântula.

Os tratamentos de escarificação influenciaram a massa seca das raízes, no qual plântulas de diásporos que passaram por escarificação mecânica tiveram a maior biomassa. Esse resultado, provavelmente, se deve à emergência posterior das plântulas controle em relação aos indivíduos que foram escarificados, uma vez que a escarificação mecânica pode aumentar a velocidade de germinação (Arruda et al. 2015). Portanto, as plântulas que sofreram escarificação tiveram mais tempo para se desenvolverem. Esse efeito não foi observado na avaliação do crescimento inicial, porque foram selecionadas apenas as plântulas com o mesmo tempo de avaliação, não sendo incluídas aquelas que germinaram posteriormente. De forma semelhante, Soares et al. (2017) aferiram em diásporos de Tectona grandis que a massa seca das plântulas variou significativamente entre os tratamentos de escarificação, e as variáveis de crescimento não. Os autores explicaram que a maior produção de matéria seca pode estar relacionada com a velocidade de germinação, posto que a maior velocidade resulta em maior tempo de translocação de reservas das sementes para as plântulas recém-emergidas (Soares et al., 2017). Como a escarificação mecânica influenciou apenas a biomassa das raízes, infere-se que esta espécie investe inicialmente no crescimento das raízes, sugerindo que se fossem avaliadas por mais tempo, observar-se-ia maior crescimento dessa parte da plântula.

\section{Conclusão}

Os diásporos de Pterodon emarginatus necessitam de tratamentos pré-germinativos para potencializar a emergência e a formação de plântulas, recomendando-se a escolha dos maiores diásporos. Diásporos maiores de $P$. emarginatus mostraram-se mais vigorosos em relação ao crescimento em diâmetro e do comprimento do caule de suas plântulas. Os tratamentos de quebra de dormência não interferiram na fase inicial de desenvolvimento das plântulas de sucupira branca, mas interferiram na massa seca total após seis meses da semeadura. Sendo 
assim, para a propagação dessa espécie o ideal é utilizar diásporos maiores selecionados por sua largura, e que seja removido parte do tegumento (escarificação mecânica). Ao se utilizar diásporos menores, a imersão em água quente (escarificação térmica) é mais indicada.

\section{Agradecimentos}

Ao Conselho Nacional de Desenvolvimento Científico e Tecnológico ( $\mathrm{CNPq}$ ) pelo financiamento do projeto (Edital CTHidro 35/2006 - Processo 555980/2006-5); pela concessão de bolsas do Programa Institucional de Bolsas de Iniciação Científica (Pibic) de NM Mota e de Produtividade em Pesquisa de YRF Nunes e GW Fernandes; à Fundação de Amparo à Pesquisa do Estado de Minas Gerais (FAPEMIG) pela bolsa de BIPDT de MDM Veloso e apoio a pesquisa (CRA-PPM-00627-16 e PPM-00539-18); ao Instituto Estadual de Florestas (IEF) e à Universidade Estadual de Montes Claros (UNIMONTES) pelo apoio logístico.

\section{Referências}

Almeida, S. D. et al. Cerrado: espécies vegetais úteis. Planaltina, DF: Embrapa-CPAC, 1998. 464 p.

Arruda, D. M. et al. Germinação de sementes de três espécies de Fabaceae típicas de floresta estacional decidual. Pesquisa Florestal Brasileira, v. 35, n. 82, p. 135-142, 2015. https://doi. org/10.4336/2015.pfb.35.82.672.

Bewley, J.D. et al. Seeds: physiology of development, germination and dormancy. New York, NY: Springer Science \& Business Media, 2013. https://doi.org/10.1007/978-1-4614-4693-4.

Biruel, R. P. et al. Germinação de sementes de Caesalpinia leiostachya (benth.) Ducke (pau-ferro) classificadas pelo tamanho e pela forma. Revista Árvore, v. 34, n. 2, p. 197-204, 2010. https:// doi.org/10.1590/S0100-67622010000200001.

Broadhurst, L. M. et al. Maximizing seed resources for restoration in an uncertain future. Bioscience, v. 66, n. 1, p. 73-79, 2016. https:// doi.org/10.1093/biosci/biv155.

Ceccon, E; et al. Is direct seeding a biologically viable strategy for restoring forest ecosystems? Evidences from a Meta-analysis. Land Degradation and Development, v. 27, n. 3, p. 511-520, 2016. https:// doi.org/10.1002/ldr.2421.

Coelho, M. C. F. et al. Germinação de sementes de sucupira branca (Pterodon pubescens (Benth.) Benth.] in vitro e ex vitro. Ciência Agrotécnica, v. 25, n. 1, p. 38-48, 2001.

Costa, P. A. et al. Quebra de dormência em sementes de Adenanthera pavonina L. Pesquisa Agropecuária Tropical, v. 40, n. 1, p. 83-88, 2010. https://doi.org/10.5216/pat.v40i1.4092.
Doussi, M. A. \& Thanos, C. A. Ecophysiology of seed germination in Mediterranean geophytes. 1. Muscari spp. Seed Science Research, v. 12, n. 3, p. 193-201, 2002. https://doi.org/10.1079/SSR2002111.

Elzenga, J. T. M. \& Bekker, R. M. Seed germination: ecological aspects-special issue editorial. Plant Biology, v. 19, n. 1, p. 3-5, 2017. DOI: $10.1111 / \mathrm{plb} .12522$.

Ferreira, R. A. et al. Morfologia da semente e de plântulas e avaliação da viabilidade de sementes de sucupira-branca (Pterodon pubescens Benth. - FABACEAE) pelo teste de tetrazólio. Revista Brasileira de Sementes, v. 23, n. 1, p. 108-115, 2001.

Fundação Biodiversitas. Listas vermelhas das espécies da fauna e da flora ameaçada de extinção em Minas Gerais. Mendonça M. P. (Coord.). 2007. Disponível em: <http://www.biodiversitas.org.br/ cdlistavermelha/default.asp>. Acesso em: 05 fev. 2014.

Inmet. Instituto Nacional de Meteorologia. Inmet 1931-2000. Disponível em: <http://www.inmetgov.br>. Acesso em: 22 nov. 2008.

Larson, J. E., et al. Seed and seedling traits affecting critical life stage transitions and recruitment outcomes in dryland grasses. Journal of Applied Ecology, v. 52, n. 1, p. 199-209, 2015.

Lima, J. R. et al. Using legumes as indicators in the seasonally dry vegetation types in South America. Ecological indicators, v. 73, p. 708-715, 2017.

Lorenzi, H. Árvores brasileiras: manual de identificação e cultivo de plantas arbóreas nativas do Brasil. Nova Odessa: Plantarum, 1992. $227 \mathrm{p}$.

Matos, P. S. et al. Superação de dormência em sementes de Pterodon emarginatus Vog. (sucupira branca) - Leguminosae (Papilionoideae). Revista Brasileira de Biociências, v. 5, n. 2, p. 720-722, 2007.

Maguire, J. D. Speed of germination: aid in selection and evaluation for seedling emergence and vigor. Crop Science, v. 2, n. 2, p. 176177, 1962.

Melo, F. P. L. et al. Recrutamento e estabelecimento de plântulas. In: Ferreira, A.G. \& Borghetti, F. (Eds.). Germinação: do básico ao aplicado. Porto Alegre: Artmed, 2004. p. 237-249.

Nascimento, H. H. C. et al. Análise do crescimento de mudas de jatobá (Hymenaea courbaril L.) em diferentes níveis de água no solo. Revista Árvore, v. 35, n. 3, p. 617-626, 2011. https://doi.org/10.1590/ S0100-67622011000400005.

Nunes, Y. R. F. et al. Pandeiros: o pantanal mineiro. MG Biota, v. 2, n. 2, p. 4-17, 2009.

Oliveira, D. A. et al. Potencial germinativo de sementes de favad'anta (Dimorphandra mollis Benth. - Fabaceae: Mimosoideae) sob diferentes procedências, datas de coleta e tratamentos de escarifcação. Revista Árvore, v. 32, n. 6, p. 1001-1009, 2008. http://dx.doi. org/10.1590/S0100-67622008000600005.

Pereira, V. J. et al. Eficiência dos tratamentos para a superação ou quebra de dormência de sementes de Fabaceae. Revista de Ciências Agrárias, v. 37, n. 2, p. 187-197, 2014.

Pereira, W. A. et al. Influence of seed size and water restriction on germination of soybean seeds and on early development of seedlings. Journal of Seed Science, v. 35, n. 3, p. 316-322, 2013. http://dx.doi. org/10.1590/S2317-15372013000300007. 
Popinigis, F. Fisiologia da semente. Agiplan, Brasília, DF, 1977. $289 \mathrm{p}$.

Prado Júnior, J. A. et al. Estrutura da comunidade arbórea em um fragmento de floresta estacional semidecidual localizada na reserva legal da Fazenda Irara, Uberlândia, MG. Bioscience Journal, v. 26, n. 4, p. 638-647, 2010.

R Development Core Team. R: a language and environment for statistical computing. Vienna, [2011]. Disponível em: $<$ http://www.Rproject.org>. Acesso em: 10 july 2014.

Reis, G. G. et al. Estudos sobre a dormência de sementes de sucupira (Pterodon pubescens): tratamentos para a superação de dormência. 1985. Revista Árvore, v. 9, n. 1, p. 49-57, 1985.

Reis, G. G. et al. Germinação de sementes de essências florestais. Pesquisa Agropecuária Brasileira, v. 15, n. 1, p. 97-100, 1980.

Rose, S. \& Poorter, L. The importance of seed mass for early regeneration in tropical forest: a review. In: Ter Steege, H. (Ed.) Long term changes in composition and diversity: case studies form the Guyana Shield. [S. 1.]: Tropenhos Foundation, 2002. p. 19-35.

Saboya, P. \& Borghetti, F. Germination, initial growth, and biomass allocation in three native Cerrado species. Brazilian Journal of Botany, v. 35, n. 2, p. 129-135, 2012. http://dx.doi.org/10.1590/ S0100-84042012000200002.

Saldanha, C. W. et al. Weight is a key factor in the physiological quality of Parapiptadenia rigida seeds. Pesquisa Florestal Brasileira, v. 38, p. 1-7, 2018. http://dx.doi.org/10.4336/2018. pfb.38e201701501.

Santos, A. P. et al. Composição química, atividade antimicrobiana do óleo essencial e ocorrência de esteróides nas folhas de Pterodon emarginatus Vogel, Fabaceae. Revista Brasileira de Farmacognosia, v. 20, n. 6, p. 891-896, 2010. http://dx.doi. org/10.1590/S0102-695X2010005000052.

Silva, D. L. et al. Emergência e estabelecimento de plântulas de Guazuma ulmifolia Lam. em função de diferentes tratamentos prégerminativos. Ciência Florestal, v. 26, n. 3, p. 763-772, 2016. http:// dx.doi.org/10.5902/1980509824205.
Smith, P. The book of seeds: a lifesize guide to six hundred species from around the world. London: Ivy Press, 2018.

Soares, G. O. D. S. et al. Methods for overcoming dormancy in teak diaspores. Pesquisa Agropecuária Tropical, v. 47, n. 4, p. 384-389, 2017. http://dx.doi.org/10.1590/1983-40632017v4749762.

Souza, A. D. G. et al. Correlation of biometrical characteristics of fruit and seed with twinning and vigor of Prunus persica rootstocks. Journal of Seed Science, v. 38, n. 4, p. 322-328, 2016. http://dx.doi. org/10.1590/2317-1545v38n4164650.

Souza, M. L. \& Fagundes, M. Seed size as key factor in germination and seedling development of Copaifera langsdorffii (Fabaceae). American Journal of Plant Sciences, v. 5, n. 17, p. 2566-2572, 2014. http://dx.doi.org/10.4236/ajps.2014.517270.

Statsoft Inc. Statistica: data analysis software system: version 10 . 2011. Disponível em: <www.statsoft.com>. Acesso em: 10 ago. 2013.

Statton, J. et al. Identifying critical recruitment bottlenecks limiting seedling establishment in a degraded seagrass ecosystem. Scientific Reports, v. 7, n. 1, p. 14786. 2017.

Terra, L. B. et al. Aspectos morfológicos do fruto, semente e desenvolvimento pós-seminal de sucupira-branca (Pterodon emarginatus Vog. - Fabaceae). Revista Agro Tropical, v. 9, p. 3654, 2007.

Therneau, T. A package for survival analysis in S. R package version 2.37-7. 2014. Disponível em: <http:/CRAN.R-project.org/ package $=$ survival $>$. Acesso em: 15 out. 2015.

Vendramin, D. W. \& Carvalho, R. I. N. Qualidade fisiológica de sementes de pitangueira (Eugenia uniflora L.) (Myrtaceae). Estudos de Biologia, v. 35, n. 84, p. 59-65, 2013. https://doi.org/10.7213/ estud.biol.7850.

Westoby, M. et al. Plant ecological strategies: some leading dimensions of variation between species. Annual Review of Ecology and Systematics, v. 33, n. 1, p. 125-159, 2002. https://doi. org/10.1146/annurev.ecolsys.33.010802.150452.

Zar, J. H. Biostatistical analysis. 5th ed. Upper Saddle River, New Jersey: Prentice Hall, 2010. 